\title{
UM CASO DE MEGACOLON CURADO PELA AMPUTAÇÃO PERINEAL INTRAESFINCTE- RIANA DO RETO
}

\author{
ALIPIO CORREIA NETO \\ Catedrático de Clínica Cirúrgica da Faculdade de Medicina da Universidade \\ de São Paulo
}

O megacolon, mormente o megacolon adquirido, é afecção comum entre nós. No meu serviço da Santa Casa, temos anualmente cerca dé 10 casos, perfazendo no total, desde que assumimos a regência da $1 .^{a}$ catedra de Clínica Cirúrgica, em fins de 1935, cerca de 40 casos. Material relativamente abundante para o qual temos uma atenção especial, e nossas idéias vão evoluindo a medida que vamos colhendo resultados da terapêutica cirúrgica que, ha 7 anos, propuzemos para cura deste mal.

Nosso intuito neste artigo é relatar um caso muito rebelde a toda especie de tratamento, curando-se, no entanto, por meio de uma operação inteiramente nova. A òperação é nova, mas a sua aplicação está amparada nos modernos conhecimentos sobre a patogenia do megacolon, para cujo esclarecimento muito tem contribuido os estudos. feitos em a nossa Faculdade.

Segundo o conceito que admitimos como verdadeiro, o megacolon é consequência da acálasis dos esfincteres lisos encontrados, no intestino grosso. A acálasis é uma disfunção pela qual os esfincteres não se abrem em harmonia com as constrações peristálticas do intestino, provocando estase e todas as suas consequências, isto é, a dilatação, provocada pelo excesso de conteudo, e a hipertrofia da camada muscular, devida ao esforço peristáltico contra o obstáculo oferecido pelo esfinter fechado. A concepção de acálasis é do princípio do século e pertence a Hurst. (1914). Demonstrou o próprio Hurst, em colaboração com RAKE, que a perturbação esfincteriana em apreço está vinculada a uma lesão do aparelho nervoso autônomo do intestino, os plexos nervosos de Auerbach e de Meissner. Para o colon esta verificação, isto é, a lesão dos plexos simpáticos, coube 'a CAMERON; entre nós foram confirmadas estas pesquisas por AMORIM e Correia Neto, Vasconcelos e Botelho, Etzel, Ferreira, etc. Nós estamos capacitados da veracidade desta doutrina, tão convencidos estamos, baseàdos nessas verificações, foi que propuzemos um novo tratamento do megacolon, que consiste na inutilização, pela resecção, do esfincter responsavel. E tivemos o prazer de ver confirmada 
praticamente a nossa esperança de ministrar a esses doentes uma terapêutica cirúrgica eficiente.

Si o megacolon é consequente a uma acálasis esfincteriana, ele pode naturalmente ter loçalizações diversas, e isto é um fato constatado facilmente nas nossas numerosas oḅservações. $\mathrm{O}$ corolário terapêutico será então a resecção do esfincter, ou dos esfincteres que provocam o megacolon. Estes esfincteres estão catalogados num trabalho de ALoj e são em numero de sete, como se yê no esquema da fig. 1. Acontece, no entanto, que nem todos autores concordam. em que assim seja. Hurst supõe que só haja um esfincter, que é o interno do anus, ao qual responsabilisa por todos os caşos de megacolon. A patologia mostra que istổ é úm erro, pois ha casos de megacolon direito, do ascendente, conservando o calibre normal todo, o intestino à esquerda do angulo hepático, como já observamos. $\mathrm{Na}$ figura esquemática que ilustra o seu livro, VAsconcellos e Botel ho, acrescem aos esfincteres assinalados por ALoJ mais um, ao nivel da desembocadura do ileó. Borcesco e Corneano assinalam 3 esfinteres a mais no colon transverso e um no ceco. Estas citações tem por objetivo mostrar que os autores não são concordes na localização destas formações anatômicas. Possivelmente algumas escaparam a argúcia dos pesquizadores. Distọ estamos convencidos. Ao nivel do reto, por exemplo, abaixo do esfincter pelvi-retal, deve haver formaçôes que explicam o insucesso das esfincteretomias pelvi-retais combinadas com a resecção do esfincter interno do anus. Isto mais de uma vez temos verificado; mesmo depoịs da concenciosa resecção ampla do esfinter pelvi-retal permanece um megasigma; fato tambem constatado por FERREIRÄ.

$\mathrm{Na}$ observação que transcrevemos, que deve ser lida com atenção, verificou-se este fato, isto é, depois da cuidadosa resecção do esfincter pelvi-retal, praticada duas vezes em duas sessões cirúrgicas diferentes, persistiu o mega-sigma; o estudo atento das radiografias permitiu-nos observar que o ponto do obstáculo, depois da resecção do referido esfinter, não era o mesmo, estava bem mais caudal em relação ao esfincter pelvi-retal. Concluimos tratar-se de formação esfincteriana em pleno reto, que ainda não fora assinalada pelos anatomistas, causadora, no nossio caso, do obstáculo, portanto, a razão da recidiva do megacolon. Devido à sua proximidade do anus, resolvemos amputar o reto logo acima do ponto estreitado, porque pareceunos o meio mais eficiente de eliminar tal esfinter, que 'já causara ao doente $o$ inconveniente de 6 operações anteriores. $O$ doente aceitou o nosso alvitre e tivemos o prazer de vê-lo curado, conforme se de-. duz da observação: 
B. O., 26 anos, branco, brasileiro, solteiro (3-4-1937):

Queixa: Constipação e tumor abdominal ha 2 anos.

Molestia atual: Desde a infância sofre de constipação, passava 4 a 5 dias sem evacuar, alternando com periodos de evacuações diárias. Por causa disso, até aos 10 anos de edade, fazia uso frequente de lavagens e purgativos. Desta epoca em deante melhorou progressivamente até que, durante um periodo de 14 anos, passou a evacuar expontaneamente todos os dias. Algumas vezes as evacuações eram diarreicas, mas o comum era serem pastosas. De dois anos para cá passou a sofrer novamente de prisão de ventre por 2 a 3 dias intercalados de períodos de evacuações normais durante 10 dias mais ou menos, progressivamente, ho entanto, os dias de constipação foram aumentando e diminuindo o intervalo em que evacuava bem. Assim sendo, de 1 ano e meio a esta parte passou a usar novamente lavagens e purgativos; afim de exonerar o intéstino. No último ano, mesmo com purgativo ou lavagens, percebe que não esvasia o intestino inteiramente, alguma parte fica sempre retida. Nesses dois anos, sente dores abdominais, sob forma de cólicas, que melhoram com a evacuação. Ǔltimamente, não usando purgativos, pasșa até um mez sem evacuar. Ao dar entrada no Serviço não evacuava ha 20 dias. Sente uma bola muito grande e muito dura, que ocupa quasi todo o ventre, sendo mais perceptivel ao tacto no hipogastrio. Emagreceu sensivelmente. Tem apetite, come bem mas a digestão é dificil, sente-se ansiado. Enfraqueceu muito. Sente palpitações é cansa-se facilmente quando anda.

Nega passado sifilítico. Fuma 3 a 4 cigarros ao dia. Não bebe.

Exame físico: A inspecção geral, nada apresenta digno de nota. Pele seca; emagrecido, panículo adiposo escasso; mucosas pouco coradas. 48 quilos de peso. Pulso 62 batimentos. - Pressão arterial $120-80$.

Exame dos pulmões, nada revela a assinalar.

Coração, nada digno de nota ao exame propedêutico.

Abdomen: Abaulado e assimétrico, assimetria provocada por uma elevação que invade o hipogastrio, fossa iliaca esquerda e hipocrondrio do mesmo lado.

À palpação nota-se um tumor enorme, duro, bem delimitado que, para baixo, penetra na bacia e, para cima, se perde sob o rebordo costal. Embora de consistencia dura o tumor deixa-se deprimir pela pressão dos dedos. O sintoma do descolamento mucoso é muito nítido (Klebesyntom).

Exames de laboratorio: Raios X: "Mégasigma com fecaloma provavelmente por acalasis do esfincter pelvi-retal". (Dr. Cassio Villaça) (Fig. 2).

Wassermann: negativo. Taxa de hemoglobina: $80 \%$. Urina: negativo.

Eletrocardiograma: Desvio do eixo para a esquerda (Dr. Pazzanezze'). Metabolismo básico: - 3\%.

Diagnóstico: megasigma com fecaloma.

Tratamento: Com auxilio de purgativos e lavagens conseguiu-se esvasiar o fecaloma e foi indicada a operação.

1. ${ }^{2}$ OperaçÃo: 20-4-1937: Operador - Dr. Etzel, anestesia peridural alta (novocaina a $2 \%, 50$ c.c.). Laparatomia umbélico-pubiana. Foi feita' a esfincterectomia pelvi-retal segundo a tecnica de Corrêa Netto: "Resecção de uma fita muscular de $2 \mathrm{cms}$. de largura por 10 de comprido". Peritonização.

Posoperatorio sem acidentes, mas o doente não evacua expontaneamente. 20 dias depois reconstituiu-se o fecaloma, como mostra a radiografia, fig. 3. Em face deste resultado, supoz-se que a acalasis era tambem do esfincter interno do anus.

2. ${ }^{a}$ Operação: 19-6-1937: Dr. Zerbini. Anestesia geral (balsoformio). Foi feita a esfincterectomia do esfincter interno do anus, segundo a tecnica de Correia Neto.

Depois desta operação persistiu a prisão de ventre requerendo tratamento por meio de lavagens e purgativos o que não impediu a formação de novo fe- 
caloma, que foi extraido por manobras manuais a 30-6-37, dez dias depois da segunda operação. "A 13-7-37 houve mister de novo ęsvasiamento do fecaloma que se reproduzira. Depois desta manobra apareceram dores no baixo ventre, febre, leucocitose; formação de um abcesso na fossa isquio-retal que foi aberto pelo perineo. O paciente permaneceu. em tratamento, na enfermaria, manifestando ainda rebelde constipação, sendo necessario tiso de purgativos e lavagens 2 a 3 vezes por semana.

19-10-37 - Nova radiografia demonstrou a presença do megacolon, com fecaloma, nada tendo melhorado com as intervenções anteriores.

Em face destes resultados negativos foi feita uma nova tentativa de terapêtutica cirúrgica do megacolon, qual seja a exerese do plexo mesenterico inferior e o plexo hipogastrico superior do simpático lombo-sacro.

3. a OpEraçÃo: 20-10-1937: Operador: Alipio Correia Neto: Ráquipercainização. Incisão mediana infra-umbelical. Nota-se grande desenvolvimento do colon sigmoide. Verifica-se no reto-sigmoide a cicatriz deixada pela operação anterior. Rebate-se o sigmoide para a direita. Incisa-se o peritoneo posterior ao nivel da bifurcação da aorta abdominal. Encontra-șe o nervo pelvico (n. presacro) sob forma de plexo, disseca-se para cima, na frente da aorta até encontrar-se o plexo mesentérico inferior"; disseca-se este plexo em "volta da arteria mesenteria inferior. Resecam-se o plexo hipogástrico superiọr e o plexo mesenterico inferior em parte (Operação de Learmonth). Antes de fechar a cavidade faz-se expressão do fecaloma que é retirado por um auxiliar por via natural.

Posoperatorio: No mesmo dia o doente evacuou 3 vezes, durante a noite, expontaneamente; continuou a evacuar durante os $4 /$ dias seguintes. Após o $6^{\circ}$ dia instalou-se novamente a prisão de ventre, sendo necessario o uso de purgativos e lavagens. No entanto, neste periodo, não se formou novamente o fecaloma. " $\mathrm{O}$ doente teve alta a 3-11-37," vinte dias depois desta operação, recomendando-se voltasse depois de um mês. A fig. 4 mostra a peça operatoria os nervos simpaticos acima citados. tima operação, engordou um pouco, poude trabalhar, mas não evacuou expontaneamente durante o mês que esteve fóra, só evacuou duas vezes com auxílio de purgativo de sulfato de sódio. $\mathrm{O}$ exame físico do abdomen, nessa ocasião, revelou: Presença de cicatriz infraumbelical. Asimetria por tumor que faz saliencia no hemi-abdomen esquerdo: A palpação revela, um tumor, como anteriormente, que se identifica como unì grande fecaloma.

A radiografia revela: megasigma de grandes proporções com fecaloma. Outros exames sem importancia.

O doente permaneceu na enfermaria sem evacuar. A 20-12-37 foi feito o esvasiamento manual do fecaloma. Apezar das lavagens intestinais diariás, foi mister fazer-se novo esvasiamento 10 dias depois.

Em face do estado de constipação apresentadó pelo doente e pelo estudo das radiografias que mostram estreitamente ao nivel da parte superior do reto (fig. 5), resolvemos praticar, de novo, a esfincterectomia pelvi-retal, imaginando que, da primeira vez, não tivesse ela sido leyada até baixo, restando portanto ainda uma porção do esfincter pelvi-retal não resecado.

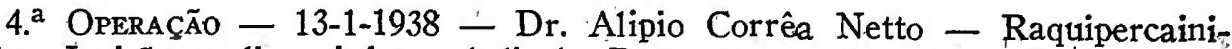
zação. Incisão mediana infra-umbelical. Reseca-se novamente o esfincter pelviretal passando a incisão ao lado da antiga cicatriz, levando-se a resecção bem baixo, depois de aberto o fundo. de saco peritoneal de Douglas, bem atraz da bexiga. A operação foi dificil por causa das aderencias numerosas entre a camada muscular e mucosá, consequentes a primeira intervenção. 


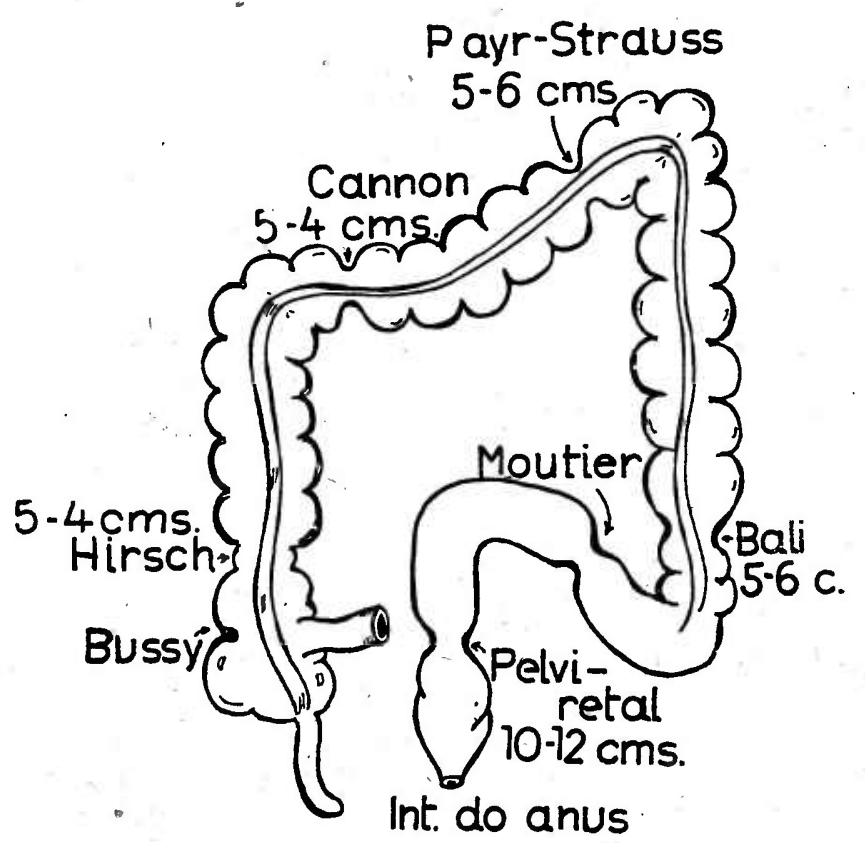

Diversos esfrictoses do colou com as suas re-pectivas dimensões. (Aloj.).

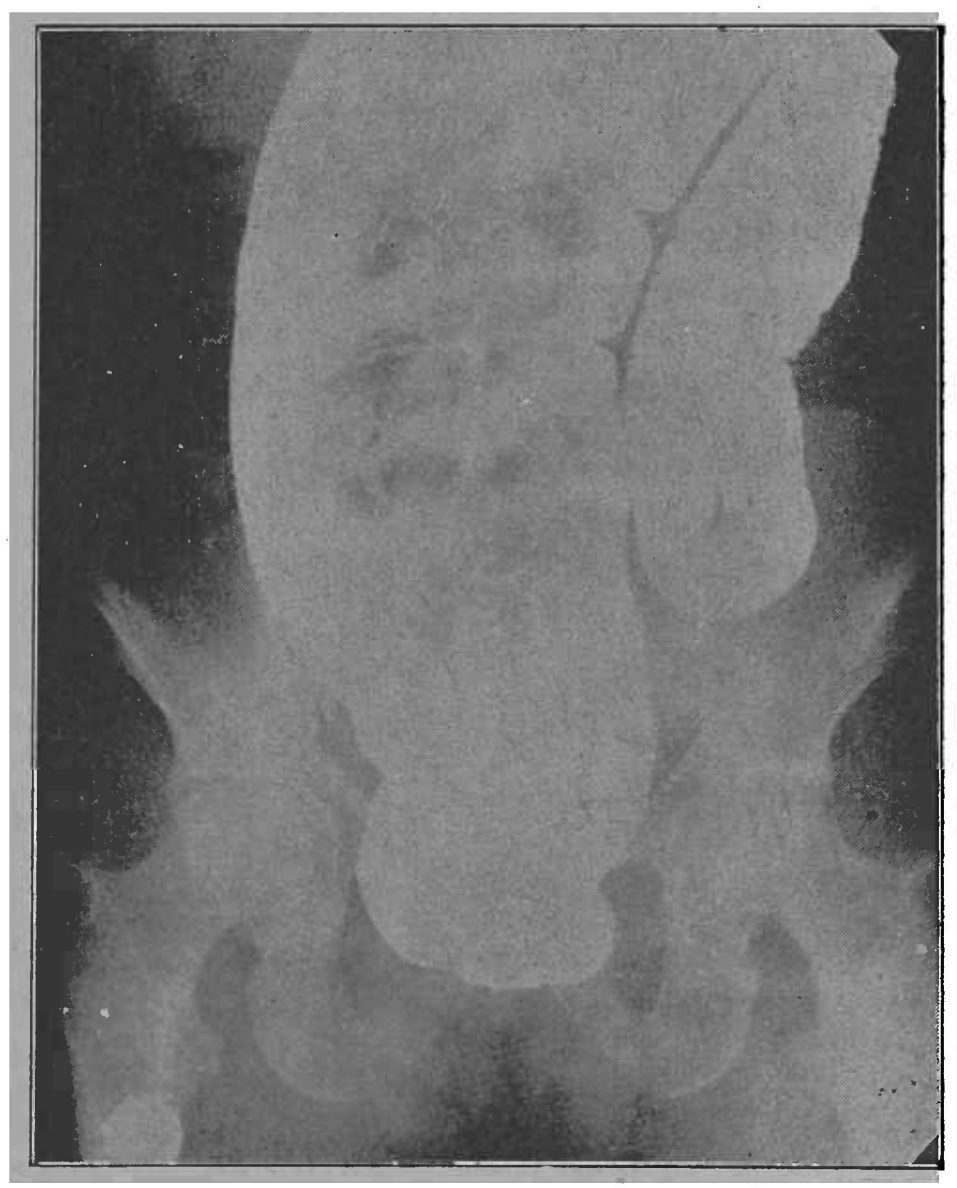

FIG. 2

Meegasigma com fecaloma (Dr. Cassio Vilaça). Enorme dilatação do colon pélvico. 


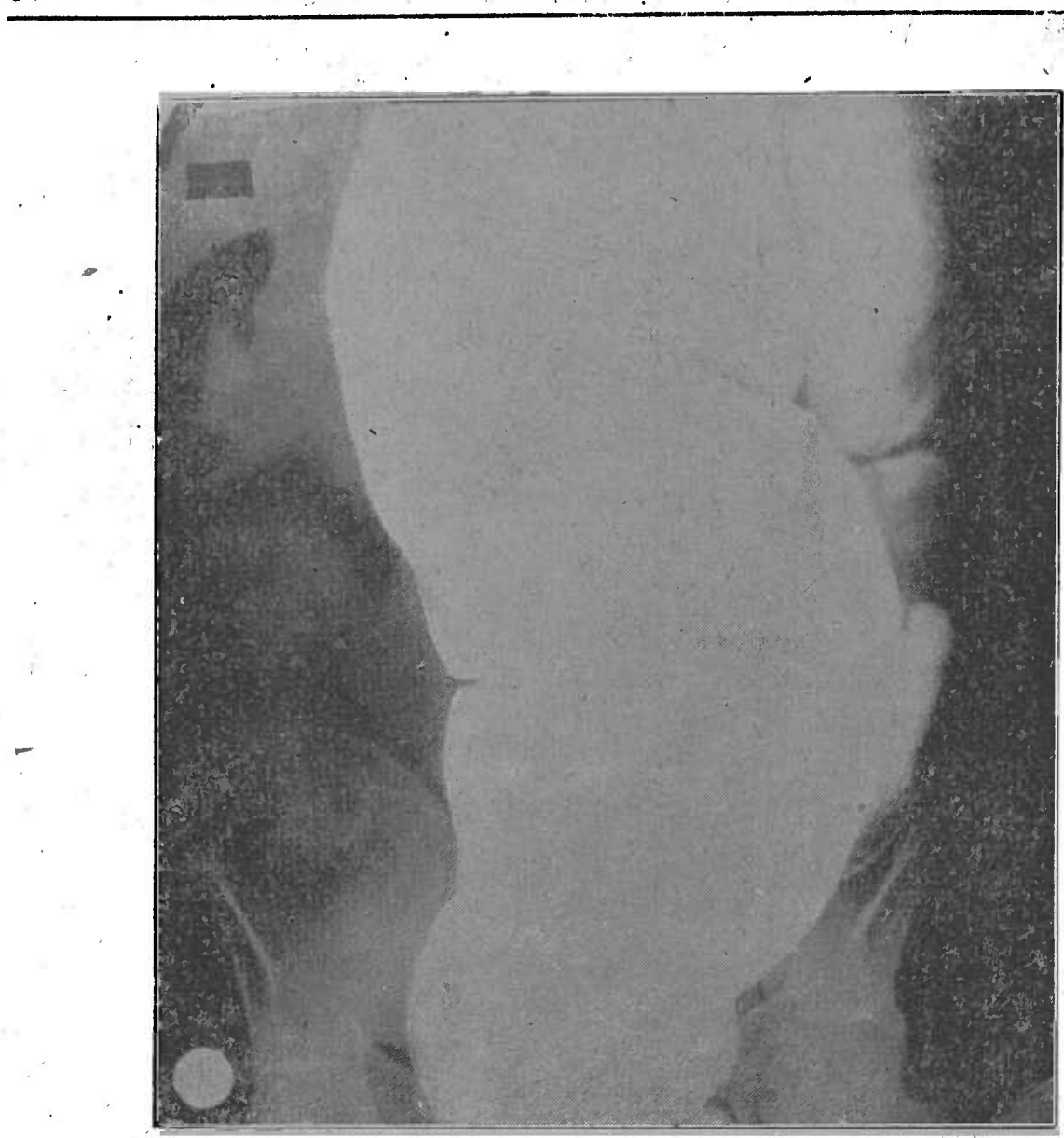

FIG. 3

3.

Vê-se ainda as enormes proporçốes do reegasigma, que não melhorou nada depois da esfrincterectomia pelvi retal

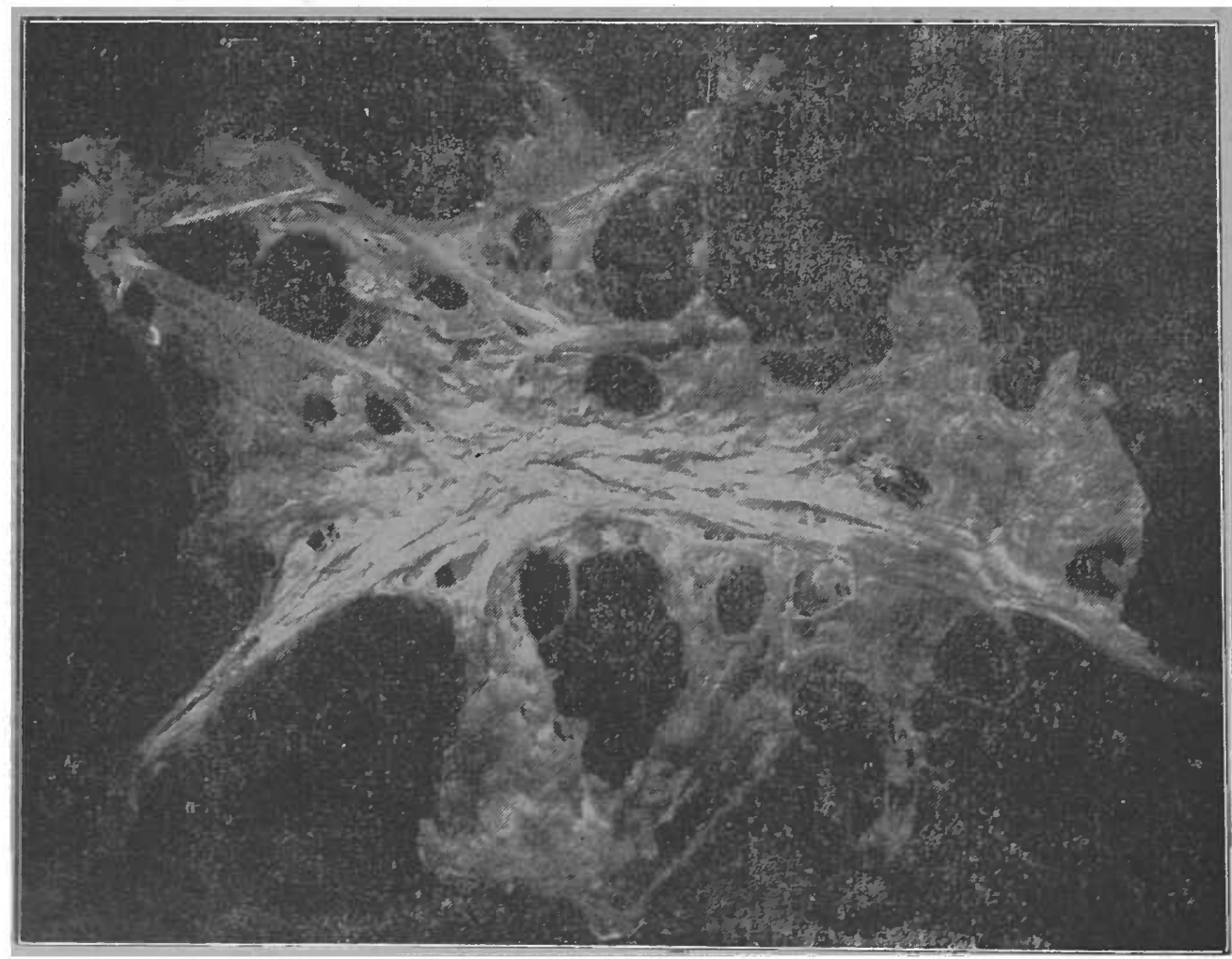

FIG. 4

Fotografia da peça operatoria onde se vê plexo hipogastrico superior (n. pce-sacro), na parte superior da figura, e o plexo mesentérico inferior 


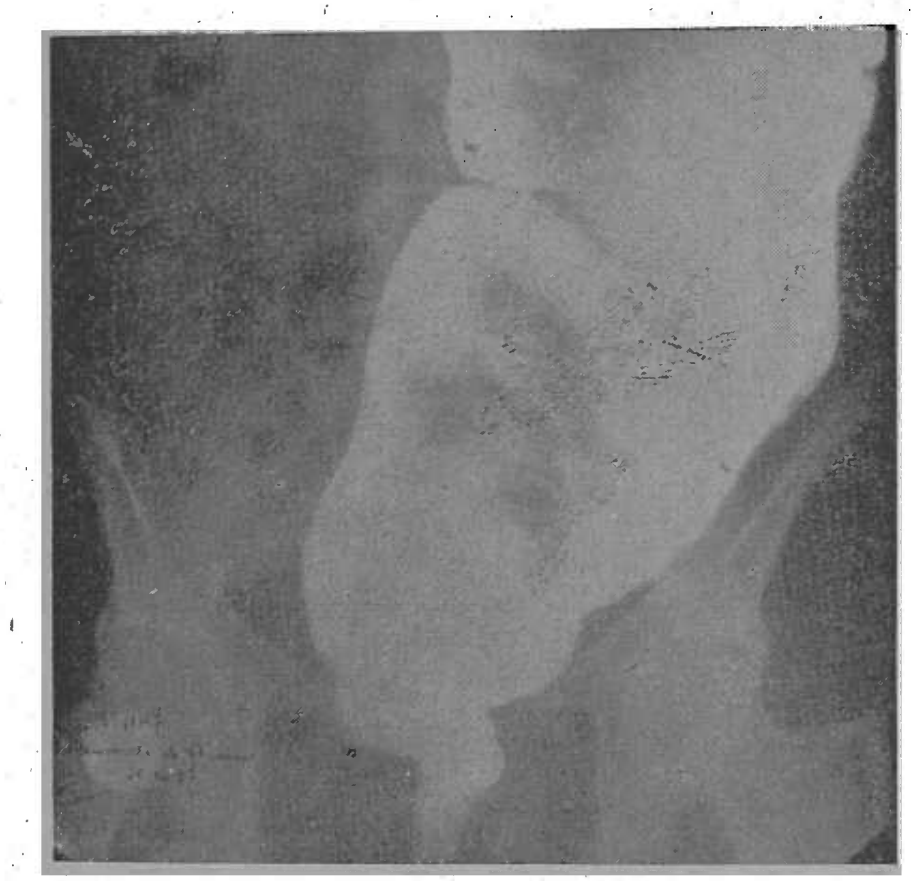

FIG. 5

Mostra enorme megasigma como o das radiografias anteriores O doente portanto não se curou depois de uma esfinctroectomia pelvi-retal (20-4-937), a esifrinctoectomia interna do anus (19-6-937) e a simpaticectomia pelvico-abdominal (20-6-937)

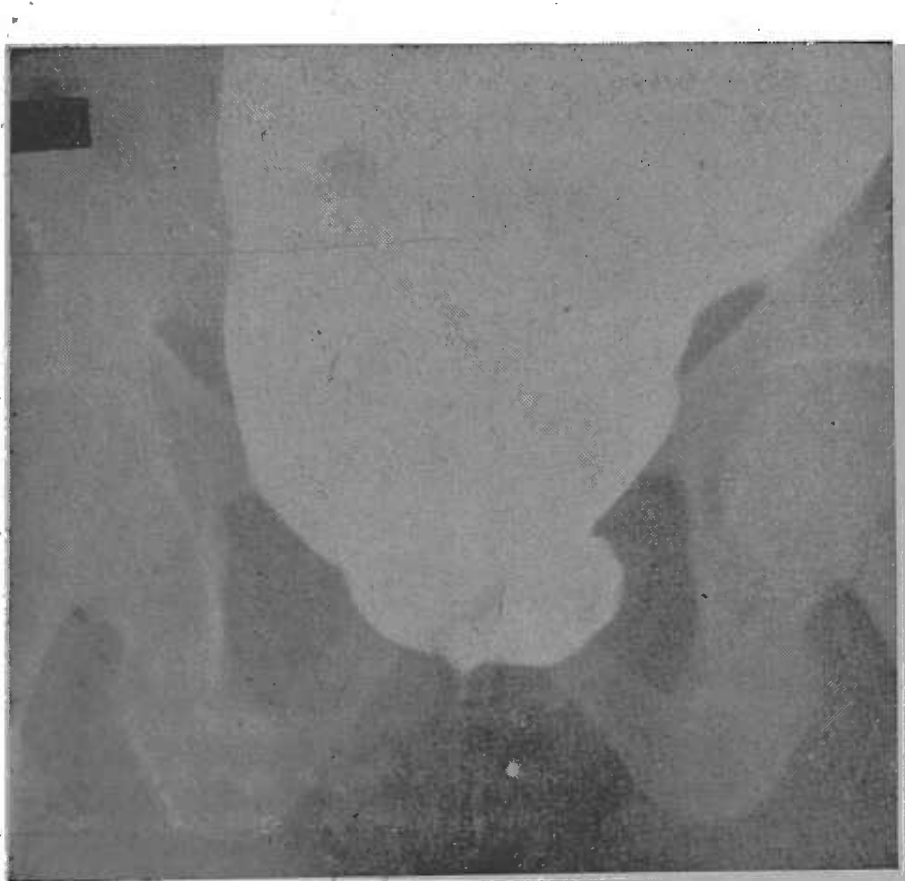

FIG. 6

Esta radiografia mostra que o ponto do obstáculo está próximo do anus, comparando com as figs. $1 ; 3$ e 5 . 

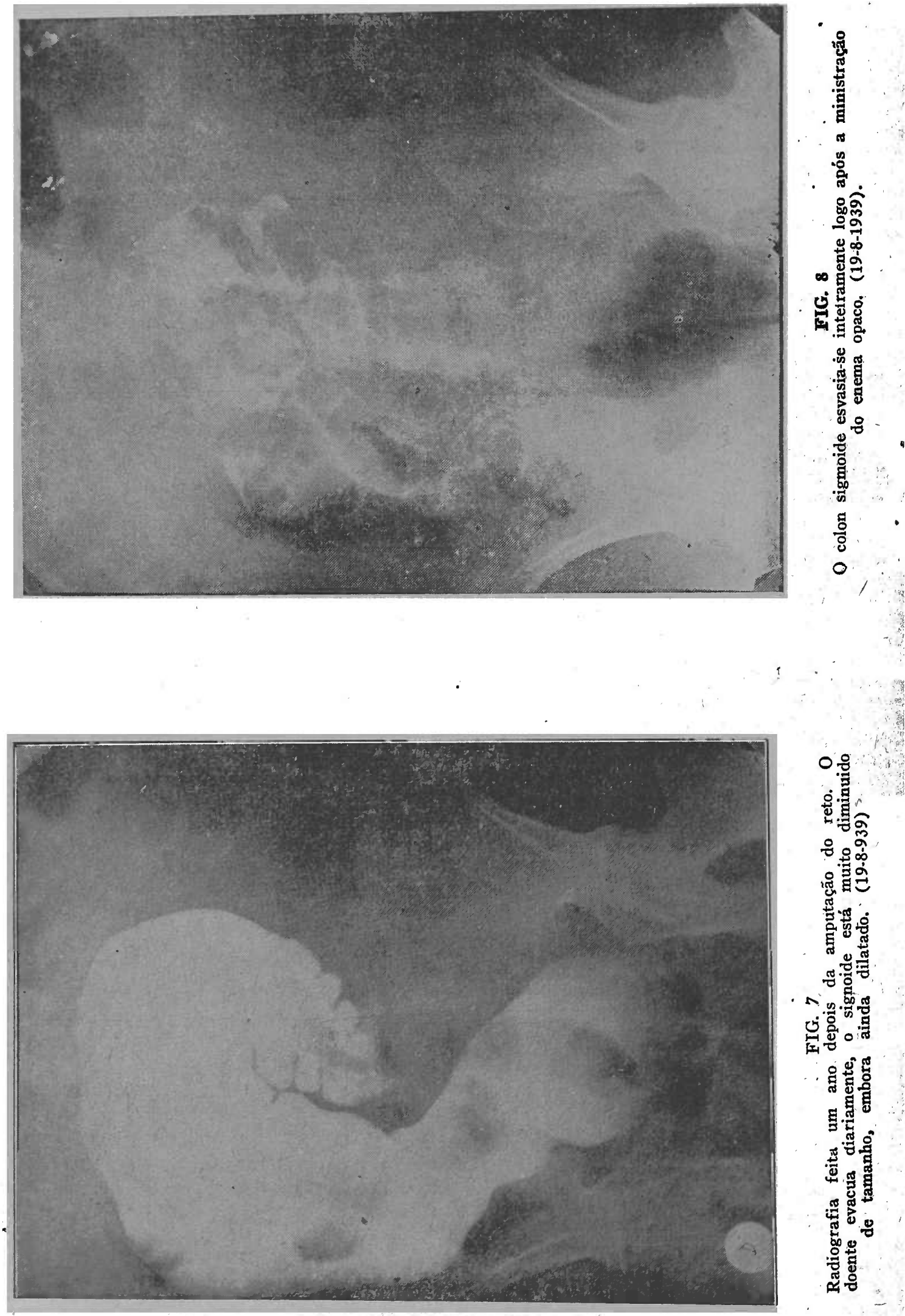


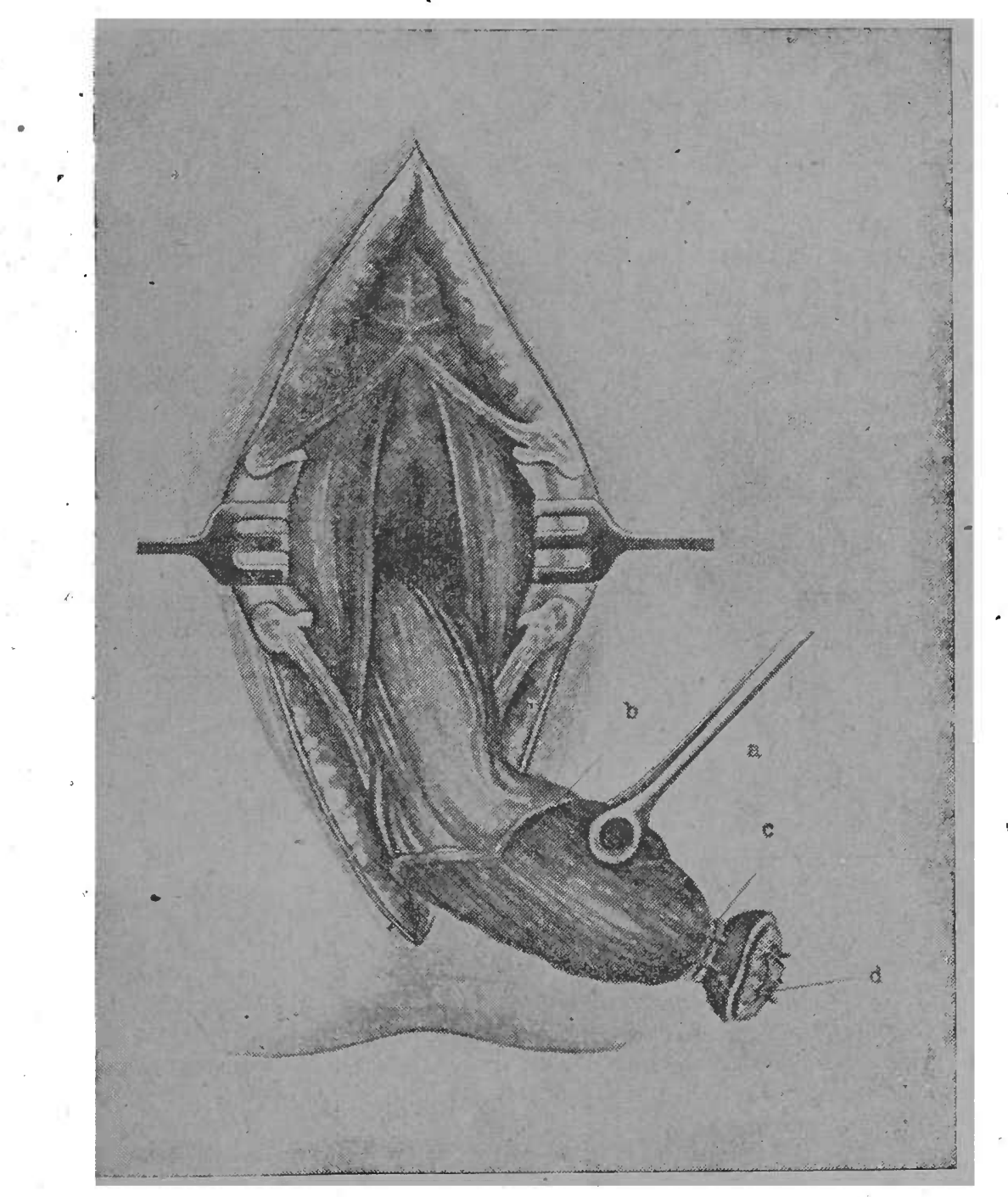

FIG. 9

Amputação intra-esfincteriana do reto, segundo Ball (Bickham.) 
A 19-1-38 evacuou expontaneamente; este fato repetiu-se nos dias consecutivos. A 5-2-1938 o paciente teve alta em boas condições, evacuando diariamente 2 a 3 vezes, mas ainda com o colon dilatado, segundo a verificação radiologica.

Em 4-5-1938; 4 meses depois da última operação, isto é, a resecção do esfinter pelvi-retal feita pela $2 i^{\mathrm{a}}$ vez, voltou o paciente novamente ao serviço. Queixa-se ainda de prisão de ventre. $\mathrm{H}_{\mathrm{a}}$ um mez não evacua. A palpação do abdomen mostra grande tumor fecal que vae da pequena bacia ao hipocôndrio esquerdo. A radiografia mostra novamente dilatação do colon sigmoide, de proporções gigantescas.

Si nós compararmos esta radiografia (fig. 6) com as anteriores, mormente, com aquelas que precederam a resecção do esfincter pelvi-retal $(1,3$ e 5$)$ vèremos que o ponto estreitado, o esfincter em acalasis está cada vez mais baixo, mais proximo do canal anal.

Em vista do insucesso impertinente destas numerosas operações, 'como o estado do "doente o permitia, resolvemos fazer a amputação da parte do reto abaixo da dilataçã̉o.

6. ${ }^{2}$ OPERAÇÃo: 21-6-1938 - Consistiu esta operação em abaixamento intra-esfincteriano do reto conforme a tecnica de Ball, representadạs na fig. 9.

O posoperatorio não foi: muito simples, houve supuração com formação de fistula para-anal que se curou depois de 20 dias.

Notou-se, desde o início, que $\mathrm{o}$ anus permaneceu perfeitamente continente. As evacuações eram irregulares, tornando-se necessario o uso de lavagenś e, às vezes, purgativos. Chegou a formar novo fecaloma que foi evacuado por via anal.

Curada perfeitamente a supuraçá̃o do perineo, o doente passou a revaçuar com auxilio de lavagens $\mathrm{e}$ tambern às vezes, expontaneamente. .

A 30-12-1938, cerca de 6 mezes depois da operaçã̃o para amputação intráaesfincteriana do reto, o paciente, enfarado do tedio da enfermaria, solicitou alta em bom estado, mas airida sofrendo de sua rebelde prisão de ventre. Sentia-se. mais forte, bem disposto e tinha vontade de trabalhar.

Voltou novamente ao Serviço a 3-8-1939. Sentia-se muito bem, evacua diariamente desde a saida do serviço, não usou mais purgativos nem lavagens, engordou e está trabalhando diariamente.

$\mathrm{Na}$ sua ficha de "follow up" está registrado:

"6-8-1939: Está passando muito bem. Evacua diariamente. Engordou, exerce seu mister de trabalhador rural com eficiencia. Esfincter anal perfeitamente continente. A radiografia mostrou grande diminuição do colon pélvico, que. ainda está aumentado. Esvasiamento completo da lavagem opaca”.

O doente está cưrado.

\section{RESUMÓ}

Doente pòrtador de megasigma.

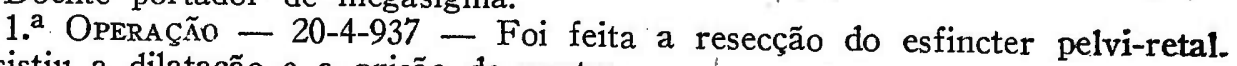
Persistiu a dilatação e a prisão de ventre.

2. ${ }^{2}$ OpERAÇão - 13-5-1937 - Resecção do esfincter interno do anus, metade esquerdà Não houve melhora.

3. a OPREAÇÃo - 19-6-1937 - Resecção do esfincter interno do. anus na metade direita. Sem resultados.

4. ${ }^{2}$ OPERAÇÃo - 20-10-1937 - Resecção do plexo sagrado superior e do plexo mesenterico inferior segundo a tecnica de Learmonth. Melhora passa-
geira de algumas semanas.

5. OPERAÇÃo - 13-1-1938 - Nova resecção do esfincter pelvi-retal, para se certificar de que a primeira não foram bem feita. Sem resultado ainda. 
6. a Operaçĩo - 11-6-1938 - Amputação do reto por via perineal com conservação do esfincter interno segundo tecnica semelhante a de Ball.

Alta a $30-12-1938$.

Volta ao serviço a 6-8-1939 completamente curado, evacuações diarias $\mathbf{e}$ normais, regressão da dilatação do colon. A cura persiste até hoje.

\section{COMENTARIOS}

Tratando-se de afecção benigna, era natural procurassemos conservar o esfincter externo, o que conseguimos perfeitamente bem usando tecnica semelhante a de BALL, segundo está relatada no tratado de Bickham, (fig. 9).'

Poderiamos então própor a presença de um novo esfincter no reto, o qual devełser tomado em consideração nos casos recidivados. Não tivemos ainda oportunidade de repetir esta operação, mas cremos que este caso é suficientemente elucidativo, uma vez que a doença resistiu a todos os tratamentos conhecidos. E o doente foi de uma notavel paciencia para se submeter a terapeutica tão importuna, qual seja a de operações consecutivas em curto espaço de tempo.

\section{BIBLIOGRAFIA}

Aloj, L. - Ricerche morfologiche sulla estrutura del colon umano in rapporto alla presenza di sfinteri anatomici. - Atti della Soc. Ital. di Anat. ano 42 (1931).

Amorim, 'M. F. e Correia Nrto, A. - Histopatologia e patogenia do megaesofago e megareto - An. Fac. Med. de São Paulo - 8:101-127; 1932.

BALL - in Bickham.

Borcesco, A. C. e Corneano, M. - Les colosphincteres e les colospasm. Masson \& Cie., 1936.

Correia NeTo, A. - Tratamento cirurgico do megacolon pela resecção dos chamados esfincteres do intestino grosso. - Rev. de Cir. de São Paulo 1:249-295; Dez. 1934.

Correia Neto. A. - Um caso de megacolon direito curado pela secção do esfincter de Cannon. - Folia Clinica e Biol. - 7:49-57; 1935.

CoRreia NeTo, A. - Etiopatogenia do megacolon.

Correia Neto, A. - Relaciones patogenicas y concomitancia de megaesofago e megacolon. - Rev. de Cir. de Buenos Aires - 13:721; 1934.

Correia Netó, A. e Etzel, E. - Le megaesophage e le megacolon devant la theorie de l'achalasie. - Rev. Sud-Americaine de Med. e Cir. 5:395$421 ; 1934$.

Etzel, E. - Megaesophagus and its Neurology - Guy's Hosptal Reports $87: 158-174 ;$ Abril 1937.

Bickram, W. E. - Operative Surgery: - Vol. V. W. B. Saunders \& Cie. 1928.

Cameron, T. A. M. - Arch. of Disease of Child. - 3:210; 1928.

Ferreira, B. - Megacolon - 1937 (Belo-Horizonte).

Hurst, A. F. - Anal Achalasia and Megacolon. - Guy's Hospital Report Vol. 4 n. ${ }^{\circ} 3$ - 1934.

Hurst, A. F. e Rake, G. H. - Achalasia of the cardia. - Quart. Med. Journ. $23: 491-509 ; 1930$.

Vasconcelos, E. e Botelho, G. - Cirurgia do Megaesofago. - Comp. Editora Nacional, 1937. 